\title{
Colonic diaphragm disease in a patient receiving long term diclofenac therapy
}

\author{
Alan A WeISS MD, DAVID A Owen MD
}

\begin{abstract}
AA WEISS, DA OWEN. Colonic diaphragm disease in a patient receiving long term diclofenac therapy. Can J Gastroenterol 1995;9(7):413-416. A 65year-old woman who had been taking diclofenac for five years developed cramping central abdominal pain. Barium enema examination was negative, but colonoscopy revealed prominent mucosal folds in the right colon with areas of ulceration. Because of continued symptoms, a right hemicolectomy was performed, which showed four separate short segment strictures or diaphragms. This case demonstrates a rare complication of nonsteroidal anti-inflammatory agent therapy that should be considered in the differential diagnosis of unexplained abdominal pain.
\end{abstract}

Key Words: Diclofenac, Drug, Nonsteroidal anti-inflammatory drug, Stricture, Ulcer

\section{Maladie du diaphragme colonique chez une patiente sous traitement au long cours par diclofénac}

RÉSUMÉ : Une femme de 65 ans, qui prenait du diclofénac depuis cinq ans, a présenté un douleur au centre de l'abdomen sous forme de crampes. Un lavement baryté s'est révélé négatif, mais la coloscopie a révélé des replis muqueux imposants au côlon ascendant, avec des zones d'ulcération. Compte tenu de la persistance des symptômes, une hémicolectomie droite a été effectuée, qui a permis de révéler la présence de quatre strictures ou diaphragmes courts. Ce cas illustre une complication rare du traitement par anti-inflammatoires non stéroïdiens qui doit être envisagée lors du diagnostic différentiel d'une douleur abdominale inexpliquée.

$\mathrm{F}$ R MANY YEARS, NONSTEROIDAL anti-inflammatory drugs (NSAIDs) have been suspected of causing large bowel disease. There are several reports implicating them in the production of right-sided ulceration (1-4) and stricture formation (5). They may also cause nonspecific colitis (6-8). Earlier reports $(9,10)$ of a condition termed 'idiopathic solitary ulcer of the cecum'

Departments of Medicine (Gastroenterology) and Pathology and Laboratory Medicine, University of British Columbia, Vancouver, British Columbia

Correspondence and reprints: Dr D Owen, Department of Pathology and Laboratory

Medicine, Vancouver Hospital and Health Sciences Centre, 855 West 12th Avenue, Vancouver,

British Columbia, V5Z 1M9. Telephone 604-875-4480, fax 604-875-4025

Received for publication February 7, 1995. Accepted April 21, 1995

indicate that one of the causes may be localized mucosal ischemia secondary to drug therapy.

Recently, however, it has become appreciated that there is a type of stricture due to NSAIDs that is morphologically unique. It consists of an extremely short segment zone of fibrosis concentrated in the submucosa with relative sparing of the muscularis propria. Because the strictures are typically less than $1.0 \mathrm{~cm}$ in length, they have been likened to diaphragms (11-17). Diaphragms have also been found in the small bowel in patients taking NSAIDs (18).

Diaphragm disease may complicate therapy with a variety of NSAIDs including diclofenac $(11,12,14,16)$, indomethacin (17), acetylsalicylic acid (ASA) $(12,15)$ and sulindac $(12,15)$. This suggests that ulceration and stricture formation are related to their pharmacological mode of action as an antiinflammatory agent, rather than a primary irritative effect.

We report an additional case of diclofenac-induced colonic diaphragm disease, which exemplifies many of the typical clinical and pathological features of the condition.

\section{CASE PRESENTATION}

A 65-year-old woman presented in August 1983 with history of diarrhea of approximately four years' duration. It started in 1979, shortly after she had a hysterectomy. At that time, she was 


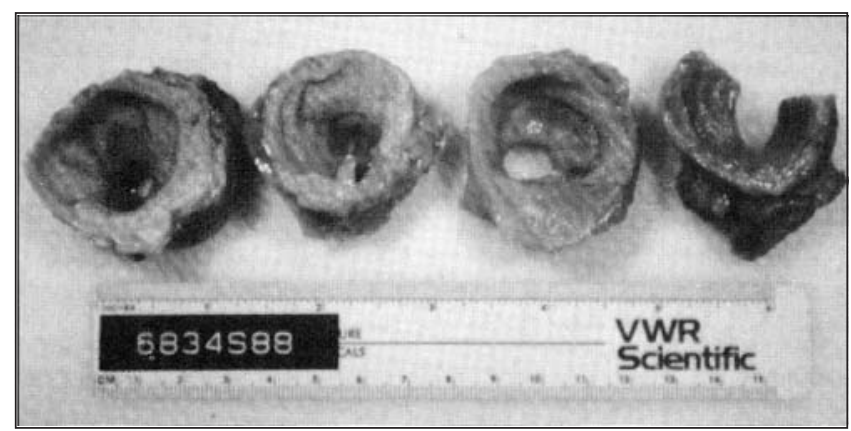

Figure 1) Gross photograph of the resected segment of colon, demonstrating the diaphragm-like nature of the stricture

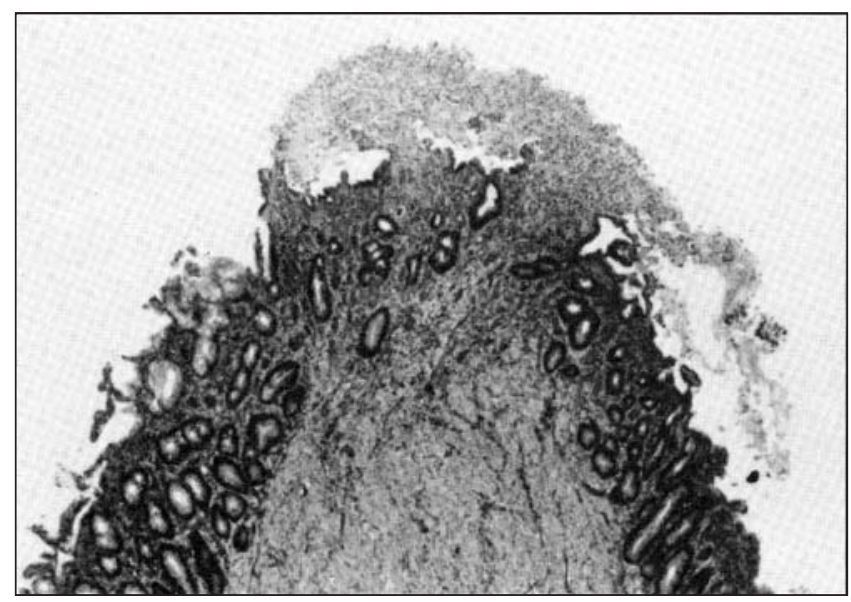

Figure 3) Superficial ulcer at the margin of the diaphragm ring

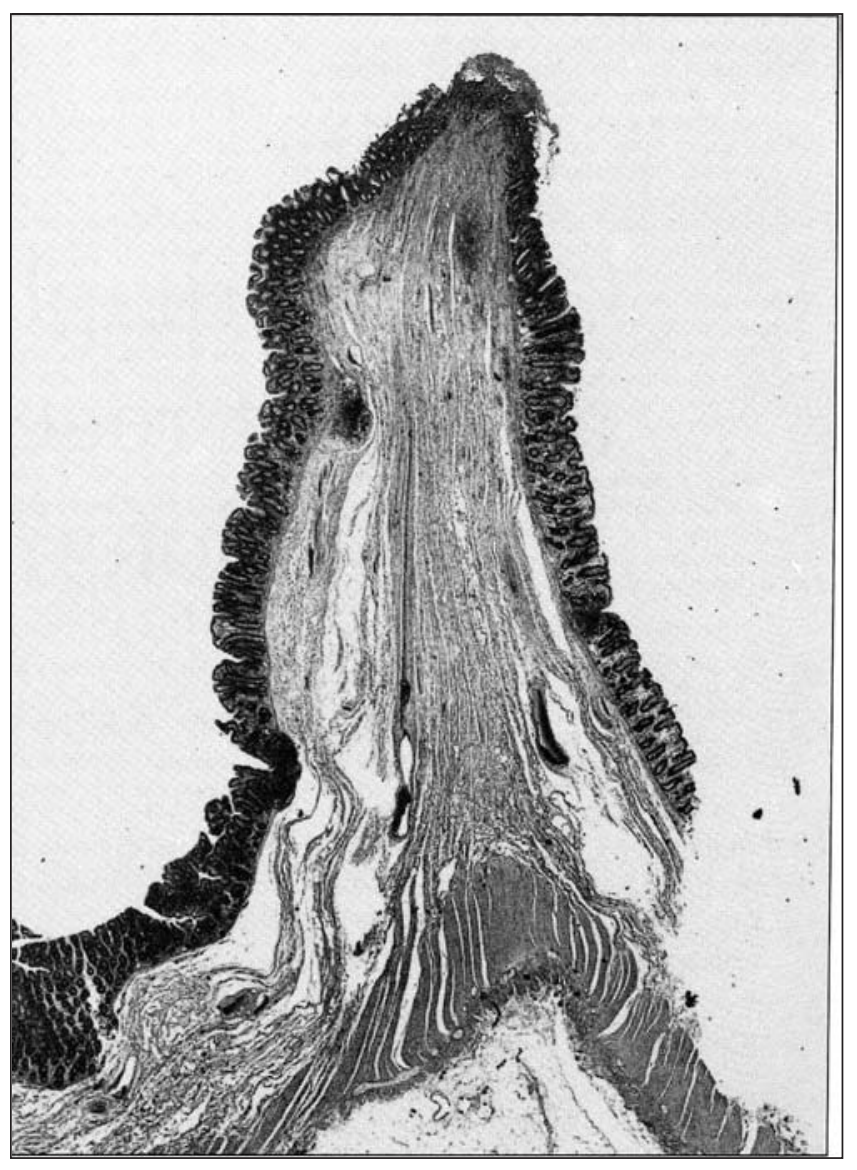

Figure 2) Diaphragm showing the greatly expanded core of fibrotic submucosa

also diagnosed with rheumatoid arthritis and was treated with intra-articular injections of steroids. Approximately three years later, in 1982, she was started on oral diclofenac $25 \mathrm{mg}$ tid. She has taken this drug continually since then with good control of her arthritis.

Her diarrhea consisted of two to six loose, watery bowel motions per day, which would occur at any time and were not related to meals. There was no nocturnal diarrhea. She did not experience any urgency or tenesmus, although she had occasional lower abdominal cramping pain before bowel movements. On examination, the patient was in good general health and no abnormality of the abdomen was detected.

In 1981, she had a sigmoidoscopy, which was negative, and a rectal biopsy, which was normal. Small bowel follow-through revealed some edema and segmental narrowing, thought to be due to spasm of the terminal ileum.
Barium enema was reported as showing small nodular defects consistent with nodular lymphoid hyperplasia and possible isolated small superficial ulcers in the ascending colon. However, these films were not available for review. Because her terminal ileum was subsequently found to be normal, the authors doubt that this initial suggestion was correct.

She was treated conservatively with psyllium hydrophillic mucilloid and loperamide. Because the diarrhea persisted, she had a follow-up air contrast barium enema in 1983, which revealed a normal colon and terminal ileum. She continued in a stable condition until the fall of 1987, when she started to complain of intermittent, dull aching in the midabdominal zone. At times, a cramping pain was present. She was found to have hypochromic, microcytic anemia, with hemoglobin of $79 \mathrm{~g} / \mathrm{L}$. Stool specimens were positive for occult blood. In December 1987 a colonoscopy was done; its results noted that she had swollen, indurated folds in the cecum. Biopsies revealed chronic inflammation with focal ulceration. She was started on Asacol (enteric-coated 5-aminosalicylic acid; Procter \& Gamble) $800 \mathrm{mg}$ qid, with some improvement of her pain and diarrhea.

During the next year (1988), she continued to be mildly symptomatic with diarrhea, anemia and stool repeatedly positive for occult blood. An upper gastrointestinal barium study and small bowel follow-up were normal. Barium enema revealed scattered diverticula, but no other abnormality. A colonoscopic examination revealed a circular diaphragmatic lesion in the hepatic flexure with a small eccentric round opening.

Because the patient continued to be symptomatic, she underwent a right hemicolectomy. Laparotomy revealed scarring in the region of the hepatic flexure, with increased vascularity of the serosa. Externally, there was slight narrowing of the colon in the hepatic 
flexure, and multiple small, firm mesenteric lymph nodes were palpable. No other abnormality was noted.

The colectomy specimen revealed four diaphragm-like strictures, located at $13,17,20$ and $27 \mathrm{~cm}$ distal to the ileocecal valve (Figure 1 ). These were approximately $0.5 \mathrm{~cm}$ in length with a $1.0 \mathrm{~cm}$ diameter central lumen, which was eccentrically placed towards the mesenteric aspect of the bowel. For the most part, the mucosa in relation to the proximal three strictures was intact, although there were multiple 1 to $2 \mathrm{~mm}$ erythematous patches present. These involved the mucosa covering the diaphragms, as well as the intervening flat mucosa. Gross ulceration was present on either side of the distal diaphragm. These ulcers measured $7 \times 2 \mathrm{~cm}$ (proximal ulcer) and $2 \times 0.3 \mathrm{~cm}$ (distal ulcer). The bowel wall was not thickened, although the serosal surface showed foci of adhesions and fat creeping round the surface. The terminal ileum was normal.

Histological examination of the diaphragm lesions (Figure 2) revealed that the essential abnormality was an expanded core of fibrotic submucosa. At the inner margin of the diaphragms there was a superficial ulcer (Figure 3 ). These showed a fibrin membrane on the surface, but this did not have the characteristic layering pattern seen in pseudomembranous colitis.

Both sides of the diaphragm were covered by a mucosa that showed patchy inflammation with occasional crypt abscess formation. The large ulcers occurring in flat mucosa were superficial and extended only into the submucosa. Beneath the ulcer bed, there was some patchy transmural inflammation, but no granulomas were identified. The erythematous patches consisted of hemorrhage into mucosal lymphoid follicles. No well defined aphthoid ulcers were seen.

\section{DISCUSSION}

NSAIDs are well known to cause a variety of upper gastrointestinal lesions, including acute erosive gastritis (19) and gastric and duodenal ulcers (20). Typically, these ulcers are not primarily related to Helicobacter pylori in- fection (21), and organisms are not present in the adjacent mucosa unless there is a coincidental infection.

NSAIDs have also been shown to cause physiological changes in the small intestine, such as an increase in mucosal permeability as assessed by the ${ }^{51} \mathrm{Cr}$ EDTA absorption test (22). The cause of this increased permeability is thought to be damage to intercellular junctions, proportional to the drug's ability to inhibit cyclo-oxygenase $(23,24)$. This damage to small intestinal mucosa may lead to a loss of blood and protein. The increase in permeability may also lead to increased mucosal exposure to intraluminal toxins and microorganisms.

Morphological abnormalities of the small bowel that have also been linked to NSAIDs include nonspecific ulceration and stricture formation. The strictures generally only involve a very short segment of bowel and may not be accompanied by localized ulceration. Diaphragm disease of the small bowel was first recognized in 1988 (25), and since then a number of publications have linked it to NSAIDs therapy. The diaphragms morphologically resemble ultrashort segment strictures and are identical to large bowel diaphragms (18).

The cause of the diaphragm formation in the ascending colon and cecum is unclear. It seems likely that diaphragm disease is only part of the spectrum of NSAID-related conditions of the large bowel. Other manifestations include nonspecific intestinal inflammation $(6-8,26)$, intestinal ulceration, particularly of the cecum $(1-4,27)$, and stricture formation $(5,25)$. The pathogenesis of diaphragm production remains obscure, but presumably it represents a minimal stricture in which the fibrosis is localized and confined to the submucosa. Lang et al (18) have postulated that the diaphragms arise as an alteration of the plicae circulares and are a precursor of more extensive flat ulceration. It seems more likely, however, that these lesions are not directly related and that diaphragms develop in ulcerated areas where the normal healing response is inhibited by the action of the anti-inflammatory drug.
In Canada, diclofenac may be prescribed as either enteric-coated tablets ( 25 or $50 \mathrm{mg}$ ) or as slow-release tablets. The slow-release preparations contain 75 or $100 \mathrm{mg}$ of the drug and are intended for once a day administration. While no specific information is available about the enterotoxic effects of each form, it may be speculated that the higher strength slow-release form may be more likely to produce strictures in the small bowel or cecum.

Our patient presented with history of chronic diarrhea and rather vague abdominal pain. She also had hypochromic microcytic anemia. These findings are typical of NSAID-induced strictures. Radiological investigation of the colon did not readily reveal any abnormality, and it was therefore necessary to proceed to colonoscopic examination. The possibility of druginduced enteropathy should be considered in a patient who is on long term NSAID therapy and presents with a history of diarrhea, abdominal pain and blood loss. Diarrhea alone, however, can occur without enteropathy. Although diclofenac is the NSAID most commonly implicated in the formation of diaphragms, other drugs, especially ASA, sulindac and indomethacin, have also been responsible. We consider that the most effective investigation of such patients is with colonoscopy and ileoscopy. The treatment should consist of discontinuation of NSAID therapy. Surgical therapy should be reserved for patients who do not respond to NSAID withdrawal or who develop significant intestinal complications.

\section{REFERENCES}

1. Debenham GP. Ulcer of the caecum during oxyphenbutazone therapy. Can Med Assoc J 1966;94:1182-4.

2. Uribe A, Johansson C, Slezak P, Rubio C. Ulcerations of the colon associated with naproxen and acetylsalicylic acid treatment. Gastrointest Endosc 1986;32:242-4.

3. Charuzi I, Ovnat A, Zirkin H, Peiser J, Sukenik S. Ibuprofen and benign cecal ulcer. J Rheumatol 1985;12:188-9.

4. Carson J, Norris WM, Orris ES. Colonic ulceration and bleeding during diclofenac therapy. N Engl J Med 1989;323:135.

5. Sheers R, Williams WR. NSAIDs and gut damage. Lancet 1989;ii:1154. 
6. Bjarnason I, Zanelli G, Smith T, et al. Non-steroidal anti-inflammatory drug-induced intestinal inflammation in humans. Gastroenterology 1987;93:480-9.

7. Abakken L, Osnes M. Non-steroidal anti-inflammatory drug-induced disease in the distal ileum and large bowel. Scand J Gastroenterol 1989;24(Suppl 163):48-55.

8. Ravi S, Keat AC, Keat ECB. Colitis caused by non-steroidal antiinflammatory drugs. Postgrad Med J 1986;62:773-6.

9. Benninger GW, Honig LJ, Fine HD. Non-specific ulceration of the cecum. Am J Gastroenterol 1971;55:594-601.

10. Butsch JL, Dockerty MB, McGill DB, Judd ES. Solitary non-specific ulcer of the colon. Arch Surg 1969;98:171-4.

11. Huber T, Ruchti C, Halter F. Non-steroidal anti-inflammatory drug-induced colonic strictures: a case report. Gastroenterology 1991;100:1119-22.

12. Whitcomb DC, Martin SP, Trellis DR, Evans BA, Becich MJ. "Diaphragm like" stricture and ulcer of the colon during Diclofenac therapy. Ann Intern Med 1992;152:2341-3.

13. Monahan DW, Starnes EC, Parker AL. Colonic strictures in a patient on long-term non-steroidal antiinflammatory drugs. Gastrointest Endosc 1992;38:385-8.

14. Fellows IW, Clarke JMF, Roberts PF. Non-steroidal anti-inflammatory drug-induced jejunal and colonic diaphragm disease: a report of two cases. Gut 1992;33:1424-6.

15. Spirnak J, Monahan DW. Colonic diaphragms associated with long-term use of nonsteroidal anti-inflammatory drugs. Am J Roentgenol 1993;160:1148-9.

16. Halter F, Weber B, Huber T, Eigenman F, Frey MP, Rudit C. Diaphragm disease of the ascending colon: Association with sustained- release Diclofenac. J Clin Gastroenterol 1993;16:74-80.

17. Pucius RJ, Charles AK, Adair HM, Rowe RCG, Hacking JC. Diaphragmlike strictures of the colon induced by non-steroidal anti- inflammatory drugs. Br J Surg 1993;80:395-6.

18. Lang J, Price AB, Levi AJ, Burke M, Gampel JM, Bjarnason I. Diaphragm disease: pathology of disease of the small intestine induced by non-steroidal anti-inflammatory drugs. J Clin Pathol 1988;41:516-26.

19. Szabo S, Spill WF, Rainsford KD. Non-steroidal anti-inflammatory drug induced gastropathy. Mechanisms and management. Med Toxicol Adverse Drug Exp 1989;4:77-94.

20. Langman MJS. Epidemiologic evidence on the association between peptic ulceration and anti-inflammatory drug use. Gastroenterology 1989;96:640-6.

21. Laine L, Marin-Sorensen M, Weinstein W. Is Campylobacter pylori (CP) prevalence lower in gastric ulcers (GUs) because of nonsteroidal anti-inflammatory drug (NSAID) use. Gastroenterology 1989;96:A282.

22. Bjarnason I, Williams $\mathrm{P}$, So A, et al. Intestinal permeability and inflammation in rheumatoid arthritis effects of non-steroidal antiinflammatory drugs. Lancet 1984;ii:1171-4.

23. Bjarnason I, Williams P, Smethurst $P$, Peters TJ, Levi AJ. Effect of nonsteroidal anti-inflammatory drugs and prostaglandins on the permeability of the human small intestine. Gut 1986;27:1292-7.

24. Fang WF, Broughton A, Jacobson ED. Indomethacin induced intestinal inflammation. Dig Dis Sci 1977;22:749-60.

25. Bjarnason I, Price AB, Zanelli G, et al. Clinico-pathological features of non-steroidal anti-inflammatory drug-induced small intestinal strictures. Gastroenterology 1988;94:1070-4.

26. Tanner AR, Raghunaty AS. Colonic inflammation and non-steroidal anti-inflammatory drug administration. Digestion 1988;41:116-20.

27. Shallman RW, Kenher M, Williams GH, Sajjad S, Sautter R. Benign cecal ulcers. Spectrum of disease and selective management. Dis Colon Rectum 1985;28:732-7. 


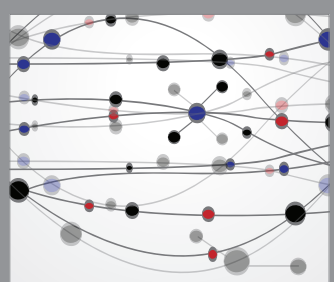

The Scientific World Journal
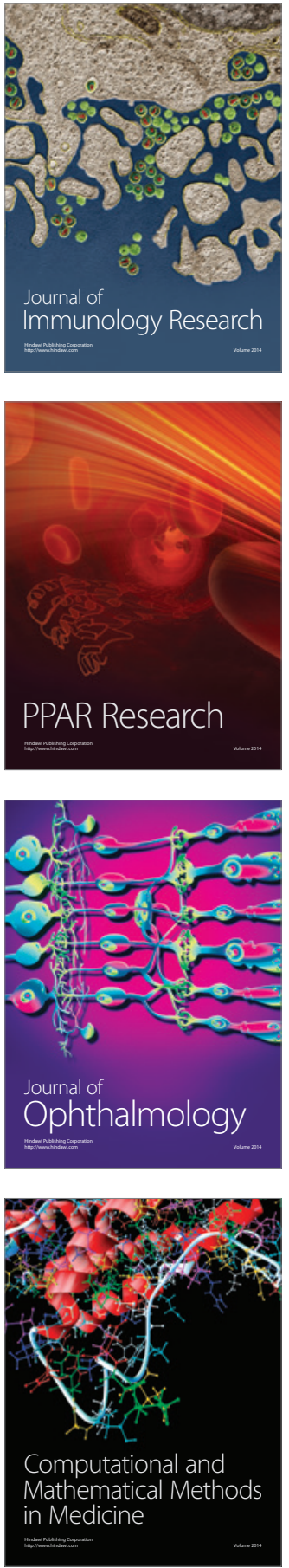

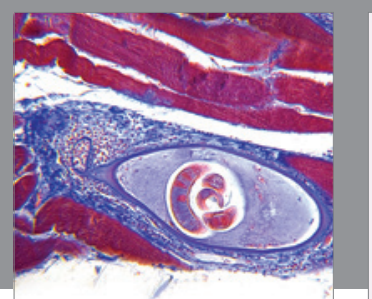

Gastroenterology Research and Practice

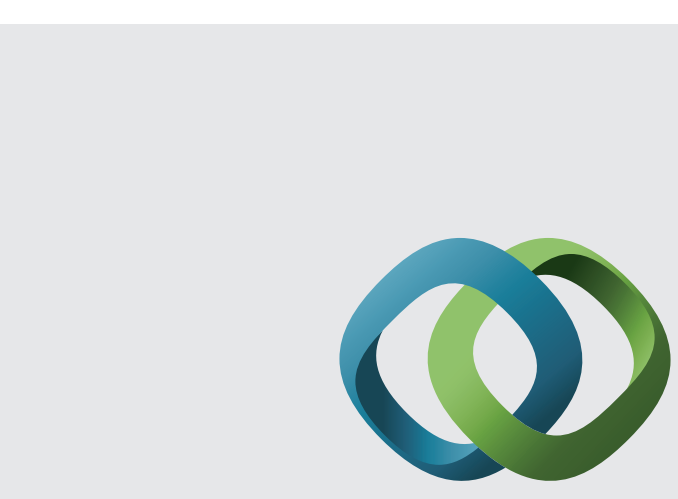

\section{Hindawi}

Submit your manuscripts at

http://www.hindawi.com
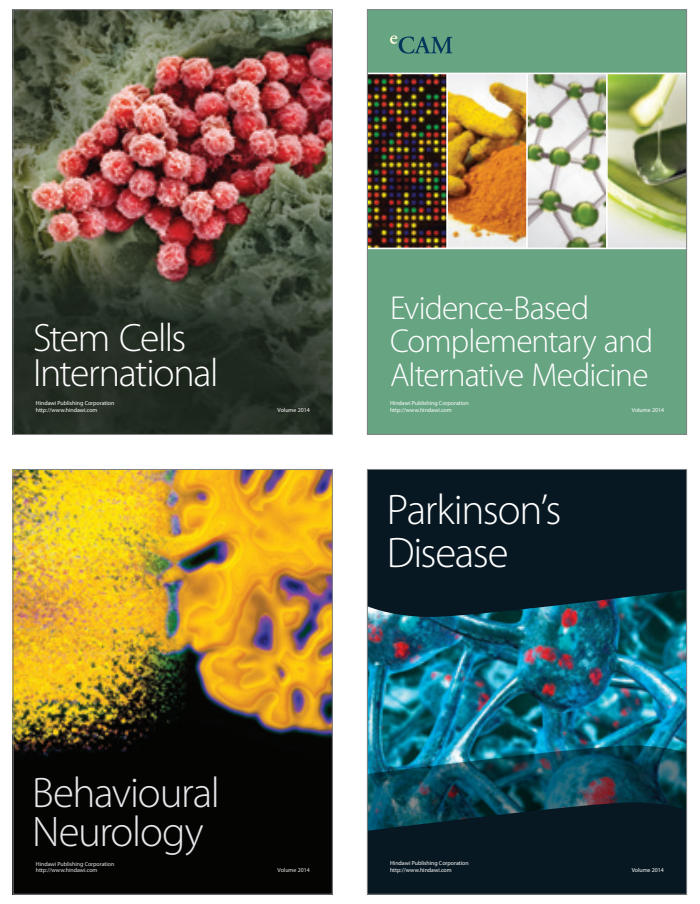
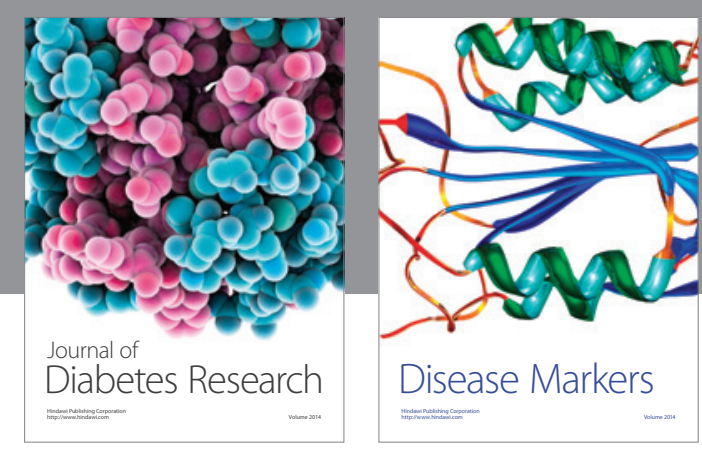

Disease Markers
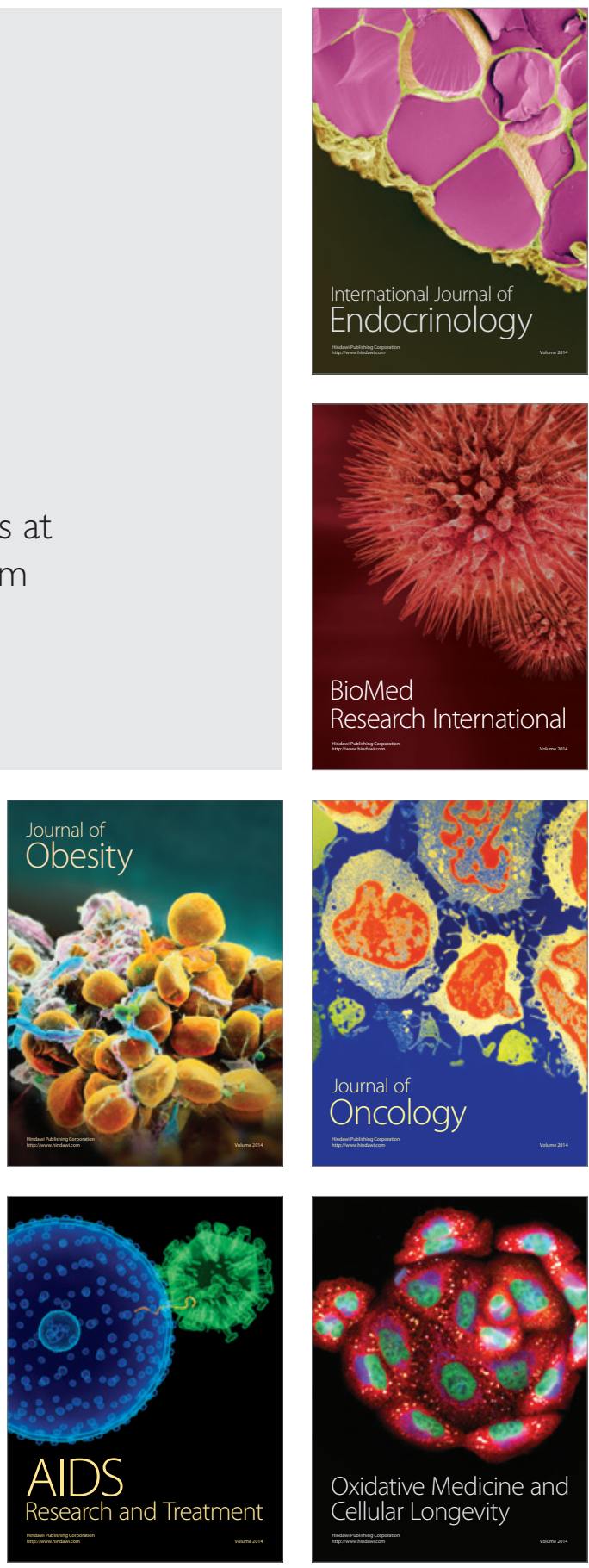